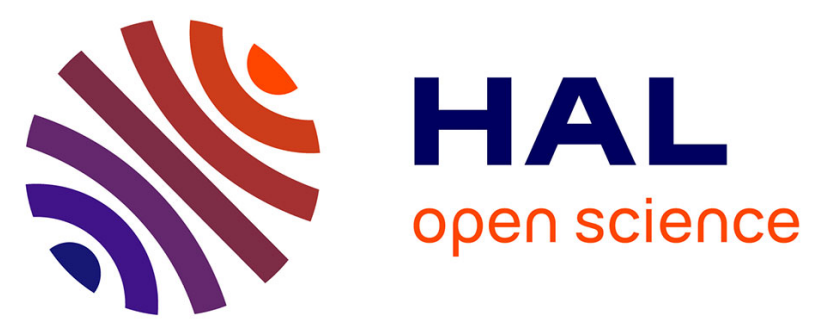

\title{
A laboratory investigation on electromagnetic bias in sea level measurements by microwave altimeters
}

\author{
Hubert Branger, Larry Bliven, Alfred Ramamonjiarisoa
}

\section{To cite this version:}

Hubert Branger, Larry Bliven, Alfred Ramamonjiarisoa. A laboratory investigation on electromagnetic bias in sea level measurements by microwave altimeters. International Geoscience And Remote Sensing Symposium, Jun 1991, Helsinki, Finland. pp.477-481, 10.1109/IGARSS.1991.579930 . hal-00853833

\section{HAL Id: hal-00853833 https://hal.science/hal-00853833}

Submitted on 26 Feb 2021

HAL is a multi-disciplinary open access archive for the deposit and dissemination of scientific research documents, whether they are published or not. The documents may come from teaching and research institutions in France or abroad, or from public or private research centers.
L'archive ouverte pluridisciplinaire HAL, est destinée au dépôt et à la diffusion de documents scientifiques de niveau recherche, publiés ou non, émanant des établissements d'enseignement et de recherche français ou étrangers, des laboratoires publics ou privés.

\section{(c)(1)}

Distributed under a Creative Commons Attribution| 4.0 International License 


\title{
A LABORATORY INVESTIGATION ON ELECTROMAGNETIC BIAS IN SEA LEVEL MEASUREMENTS BY MICROWAVE ALTIMETERS
}

\author{
H. BRANGER *, L. BLIVEN ** and A. RAMAMONJIARISOA *
}

\author{
* I.M.S.T., 12 av. Général Leclerc, 13003 Marseille France \\ ** NASA Goddard Space Flight Center/Wallops Island, Virginia 23337 USA
}

\begin{abstract}
To contribute to a better understanding of the Electromagnetic Bias in radar altimetry, a serie of experiments was conducted in the I.M.S.T. large windwave facility using a focused beam radar set at $13.5 \mathrm{GHz}$ frequency. For pure wind wave fields we found the bias to be a quadratic function of each of the commonly used parameters, namely the significant wave height, the wind speed, the water elevation skewness and significant slope. The bias divided by the significant waveheight is a linear function of these parameters. The coefficients in bias representation as a function of either the significant waveheight or the wind speed are significantly different from values obtained in field experiments. This led us to conclude that none of the latter parameters can be taken solely to account for all observed bias variations. Instead, dimensionless parameters such as the wave skewness or a dimensionless waveheight are shown to be more appropriate. They include more or less explicitely the state of development of the wind wave field of interest.
\end{abstract}

Keywords: Altimetry, Electromagnetic Bias.

\section{INTRODUCTION}

A radar altimeter determines its range by measuring the round-trip time of a pulse of electromagnetic waves to the sea-surface. The mean reflecting surface differs in elevation from the the mean sea level. The difference, called the Electromagnetic (E.M.) Bias, is probably the largest remaining source of error for which no fully satisfactory algorithm is yet established for corrections. E.M. Bias, which obviously depends on the hydrodynamicelectromagnetic properties of the sea surface, is commonly considered as a fixed percentage of the significant wave height (SWH). Such an approximation is not precise enough to achieve the range accuracy of a few centimeters required for the next spaceborne altimeter TOPEXPOSEIDON mission. Modulations of the ocean wave field by non linear wave-wave interactions, currents or residual swell would probably lead to E.M. Bias modulations that should be considered to improve the accuracy of the prediction.

Wind-wave research tank laboratory experiments enable systematic exploration of the influence of geophysical parameters on physical processes under accurately controlled and repetable conditions. Our purpose was to make simultaneous and collocated high spatial resolution measurements of both sea surface elevation and nadir backscattered power in the large I.M.S.T. wind-wave research tank $(40 \mathrm{mx} 3 \mathrm{mxlm}$ - figure $1-\mathrm{a})$ under numerous well controlled environmental conditions. A focused beam radar set at $13.5 \mathrm{GHz}$ frequency was mounted above the tank. The $3 \mathrm{~cm}$ spot size allowed us to visualize the sea wave trough/crest asymetry of the backscattered response and moreover to compute the "radar seen" sea surface wave height distribution.

Our main objectives were:

a) to compare the radar seen wave height distribution with the actual wave height distribution, the E.M. Bias beeing the difference between the means of the two distributions.

b) to relate the computed E.M. Bias values with standard geophysical parameters characterizing the wave field, such as the significant wave height, the wind speed, the wave height skewness and the significant slope.

c) to compare the wind-wave tank E.M. Bias values with open field measurements in order to give some clues for the prediction of all the observed Bias variations.

The experimental arrangement is described in section 2. Data processing procedures are detailed in section 3. Main results are shown in section 4 and discussed in section 5 .

\section{EXPERIMENTAL ARRANGEMENT}

The operating frequency was $13.5 \mathrm{GHz}$, one of the future TOPEX mission operating frequency. We used a focused beam radar set in a bistatic configuration (figure 1-b). The transmit and receive horns were located at the same but opposite $10^{\circ}$ off nadir angle. The bistatic configuration is equivalent to a nadir monostatic configuration because, in both cases the scattering facets are the zero slope facets of the sea waves. Before hitting the sea surface, the microwaves were focused by a $30^{\prime \prime}$ diameter dielectric lens. The spot size was found to be $3 \mathrm{~cm}$ at the one meter focal lenght. The dielectric lens which had been first designed by Parsons and Miller [1] for the NASA/GSFC Wallops Flight Facility, was kindly lent to I.M.S.T. The radar system we used was derived from the scatterometer designed by Bliven et al [2]. Absorbing material at appropriate locations reduced multipath reflection. The signal to noise ratio was found to be excellent, namely $60 \mathrm{~dB}$.

The mean reflected power from water surface at rest at a level h, namely $\mathrm{P}_{\mathrm{ca}}(\mathrm{h})$, was determined as follows: starting with the tank full of water, we drained it slowly while acquiring on a computer the. water level $h$ delivered by a capacitance probe, and the radar backscattered power 

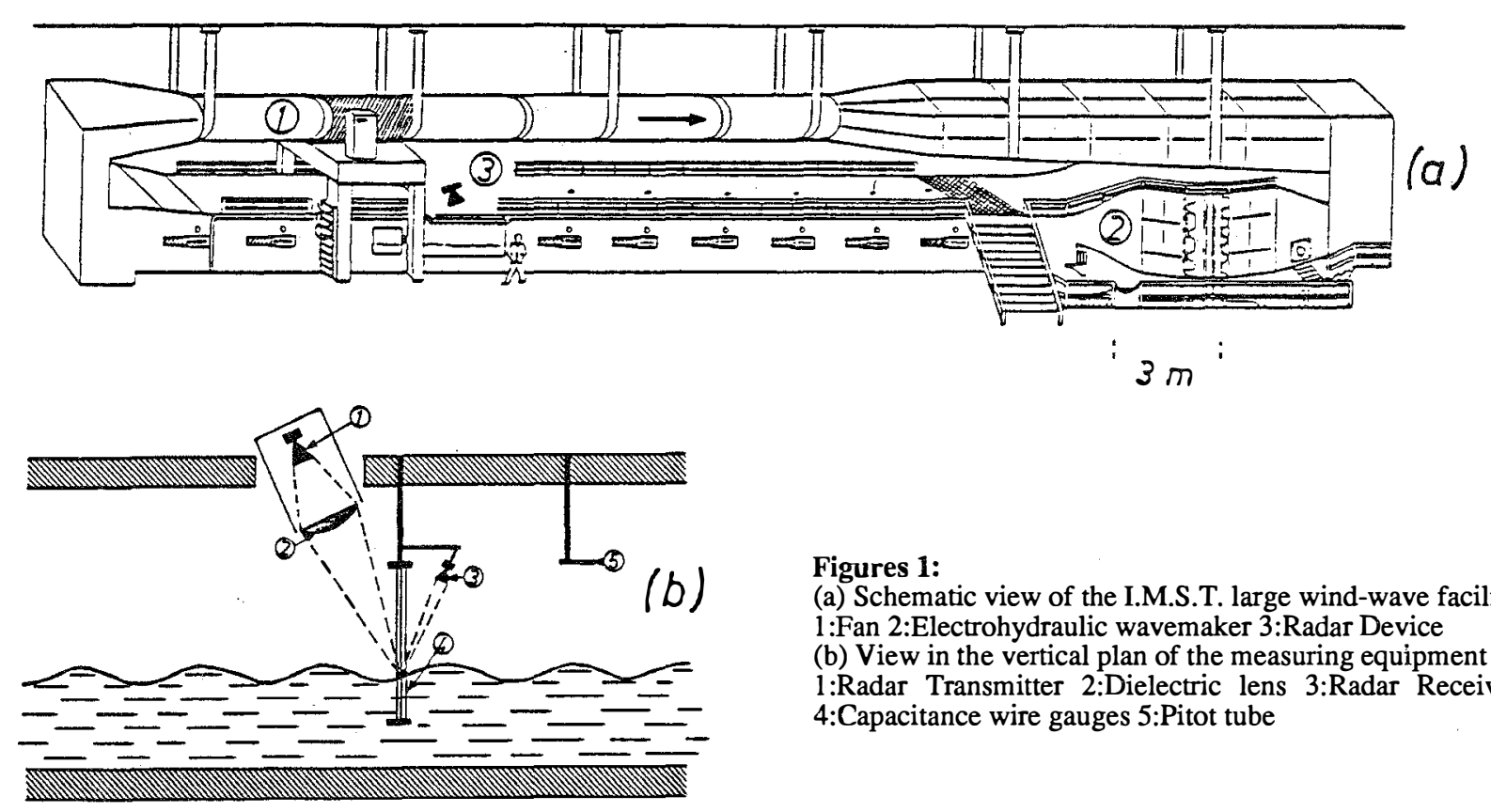

Figures 1:

(a) Schematic view of the I.M.S.T. large wind-wave facility 1:Fan 2:Electrohydraulic wavemaker 3:Radar Device (b) View in the vertical plan of the measuring equipment 1:Radar Transmitter 2:Dielectric lens 3:Radar Receiver 4:Capacitance wire gauges 5:Pitot tube

$\mathrm{P}_{\text {cal }}(\mathrm{h})$. In order to prevent the tank water height level dependence on the backscattered power, we defined a Reflectivity coefficient $r(t)$ as :

$$
\mathrm{r}(\mathrm{t})=\mathrm{P}(\mathrm{t}) / \mathrm{P}_{\mathrm{cal}}(\mathrm{h}(\mathrm{t}))
$$

$P(t)$ and $h(t)$ beeing respectively the backscattered power and the water elevation at instant $t$. $r(t)$ ranged from 0 to 1 , the maximum value corresponding to a flat horizontal sea surface all over the illuminated spot.

The water surface elevation and slopes were measured using 3 capacitance probes with $5 \mathrm{~mm}$ separation in an L. configuration located within the radar spot. The probes delivered a range measurement with a $\pm 0.2 \mathrm{~mm}$ precision. Test runs made with and without the wave gauges, showed that the reflectivity coefficients were decreased by less than $1 \%$ when the probes were present within the radar spot. The mean wind speed was measured with a Pitot tube with a precision of a few $\mathrm{cm} / \mathrm{s}$. Measurements, made at $28 \mathrm{~m}$, were free from reflection from the wave absorber.

\section{DATA PROCESSING}

Before beeing digitized at $300 \mathrm{~Hz}$ on the I.M.S.T. HP-1000 computer, the two analog $10 \mathrm{~dB}$ and $20 \mathrm{~dB}$ Gain Radar output and the three wave gauges analog signals were low-pass filtered with a cutoff frequency of $100 \mathrm{~Hz}$ to avoid aliasing effects. For each experiment run, 300000 samples per line were recorded, representing a time span per test of $16 \mathrm{~min} 40 \mathrm{~s}$.

The elevation $h(t)$ was determined from a single probe. The sea wave along-wind and cross-wind slopes were obtained by differenciating the elevation readings from two adjacent probes and dividing by the $5 \mathrm{~mm}$ spatial separation.

We combined the 10dB Gain radar signal and the 20dB Gain one to perform a double decade high precision backscattered signal $P(t)$. The reflectivity coefficient $r(t)$ was computed, as previously defined, using $P(t), h(t)$, and the calibrated Look-up table $\mathrm{P}_{\text {cal }}(\mathrm{h})$.

In order to compute the E. M. Bias, we performed a "radar seen sea surface distribution" ([1]) : the elevation measurements were sorted into a fixed number of elevation bins. If " $i$ " is the index of the elevation bin, $N_{i}$ the number of observations sorted in that bin, $\mathrm{r}_{\mathrm{ij}}$ the reflexion coefficient of sample $\mathrm{i}$ sorted in bin $\mathrm{j}$, then

- the "actual elevation pdf value" of bin number " $i$ " is equal to the ratio of the number of samples that belong to this bin to the total number of data samples:

$$
\operatorname{pdf}_{\text {Height }}(\mathrm{i})=\mathrm{N}_{\mathrm{i}} / \sum_{\mathrm{k}} \mathrm{N}_{\mathrm{k}}
$$

- the "radar seen elevation pdf value" of bin number " $\mathrm{i}$ " is set by normalizing the sum of the reflected power of all the samples that belong to this bin by the total amount of reflected power:

$$
\operatorname{pdf}_{\text {Radar }}(i)=\sum_{j} r_{i j} / \sum_{k} \sum_{n} r_{k n}
$$

The E. M. Bias, was directly derived from expressions (1) and (2) by differentiating the mean values of the two distributions:

$$
\text { E.M. Bias }=\sum_{i} h_{i}^{*}\left(\operatorname{pdf}_{\text {Radar }}(i)-\operatorname{pdf}_{\text {Height }}(i)\right)
$$

The standard deviation: $\sigma$, the skewness $: \lambda_{3}$ and the kurtosis : $\mathrm{K}_{4}$, of the surface elevation distribution and of the radar distribution were also estimated. Moreover, we computed for each experiment the significant wave height $\left(\mathrm{SWH}=4^{*} \sigma\right)$, the dominant frequency $\mathrm{n}_{0}$ of the energy containing the waves (from FFT analysis), the dominant wavelenght $l_{0}$ of the energy containing the waves (from the linear dispersion relationship for deep water gravity waves), and the significant slope ( $\left.\S=\mathrm{SWH} / 4 * 1_{0}\right)$.

\section{ILUSTRATIVE RESULTS}

A set of 93 experiments under well controlled conditions have been conducted (wind speed from 0 to $15 \mathrm{~m} / \mathrm{s}$, paddle wave generator from $1.1 \mathrm{~Hz}$ to $2.1 \mathrm{~Hz}$, and combinations of both wind waves and paddle waves). The 

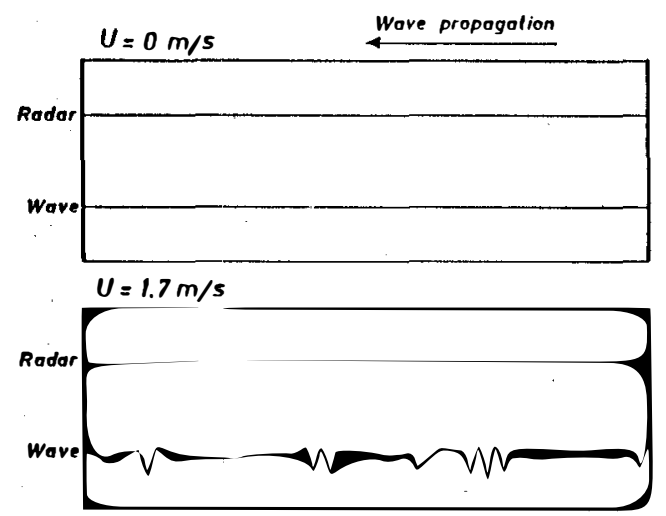

wave
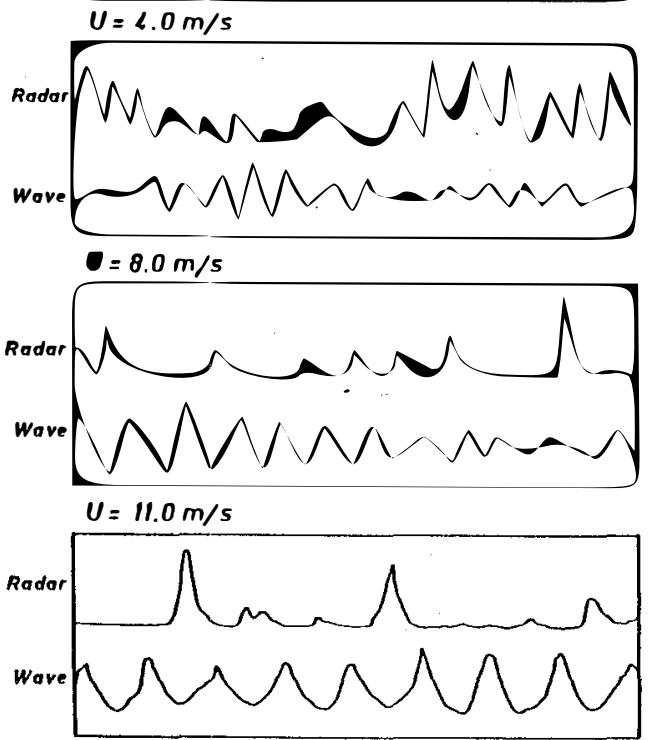

Figures 2:

(a) samples of time variations of the water deflection surface level and the reflected radar signal at various wind speed.

short presentation which follows will concern only the cases of pure wind waves. A subsequent article [3] will re:port on more detailed results from the complete set of experiments.

Figure 2(a) displays typical samples of the time variations of the water deflection level and the corresponding radar reflected signal. With the water surface at rest $(U=0 \mathrm{~m} / \mathrm{s})$ no parasitical reflection is observed. At $U=1.7 \mathrm{~m} / \mathrm{s}$, the radar appears to be sensitive to small -water surface oscillations of few centimeters wavelengths. The fact of interest with regard to the electromagnetic bias is seen at $U=2.7 \mathrm{~m} / \mathrm{s}$ and $U=4 \mathrm{~m} / \mathrm{s}$, namely, the reflection is much larger over the wave trough than over the wave crest. Then, the radar signal oscillates at the frequency of the dominant wave. For wind speed higher than about $8 \mathrm{~m} / \mathrm{s}$, a large enhancement of the reflected signal is observed in front of breaking crests. These results confirm previous observations by Lifermann [4] under similar environmental conditions whitch related the signal

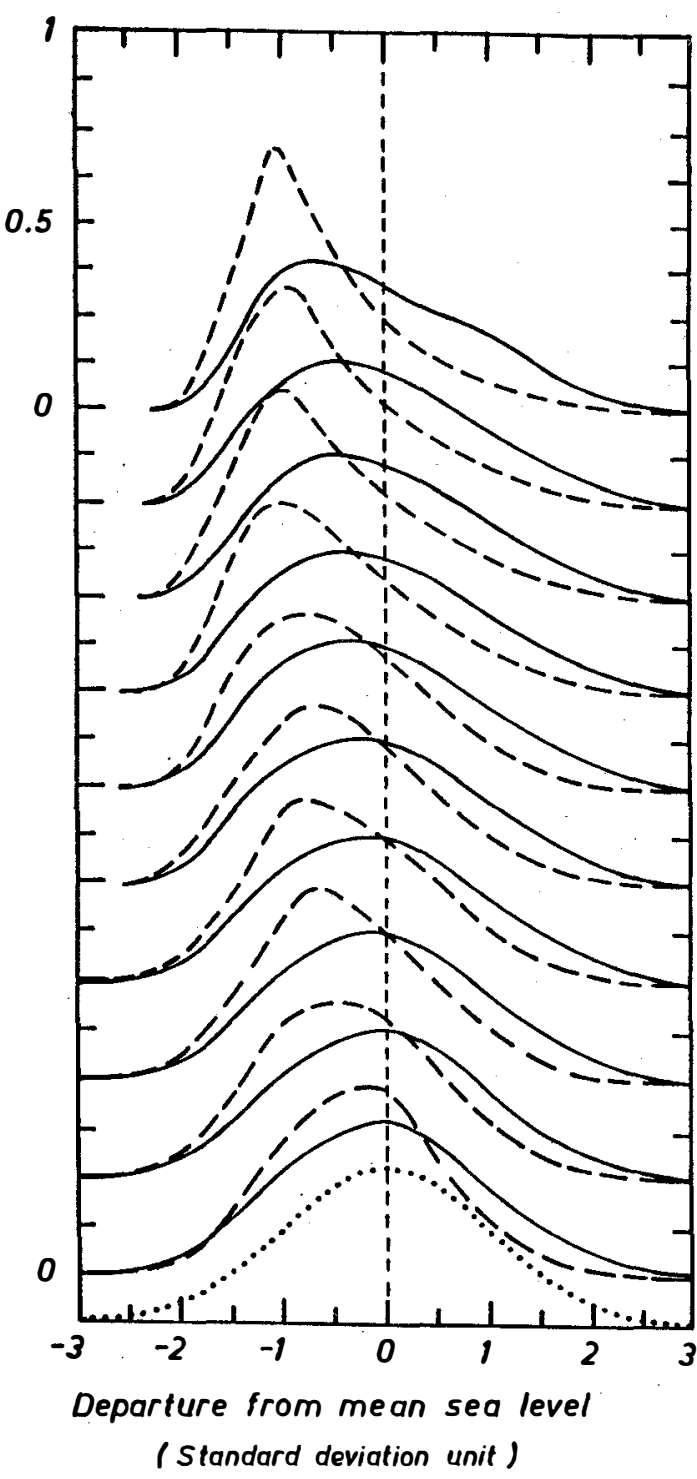

(b) probability density functions of waveheight $(-)$ and "radar seen waveheight" (- - ). Wind speed respectively: $1.7 ; 3.1 ; 4.1 ; 5.5 ; 6.6 ; 7.7 ; 8.9 ; 10.2 ; 11.6 ; 14.1 \mathrm{~m} / \mathrm{s}$, from the bottom to the top of the figure. $((\cdots . . \cdots)$ Gaussian distribution).

enhancement above the particular geometry of the breaking crests as identified by Bonmarin [5].

Figure 2(b) shows the probability density functions (p.d.f) of the actual waveheight and the radar seen waveheight as defined in section 3 with increasing wind speed. Two facts are obviously of main interest :

a) both distributions exhibit larger and larger asymetry

b) the distributions depart more and more each other, the radar p.d.f being more asymetrical than the waveheight p.d.f. Detailed investigation on the p.d.f will be found in [3].

Figure 3 shows the absolute bias as defined by expression (3) as a function of $\mathrm{U}, \mathrm{SWH}, \lambda_{3}$ and $\S$. They are commonly used parameters in analysing the electromagnetic bias. The correlation of the E.M. Bias with each of these parameters yields : 


$$
\begin{array}{llll}
\text { EM.B. }(\mathrm{cm})=.027 & -.015 * \mathrm{U}-.007 * \mathrm{U}^{2} & \left(\mathrm{r}^{2}=0.99\right) & (4) \\
\text { EM.B. }(\mathrm{cm})=.03 & -.09 * \mathrm{SWH}-.007 *(\mathrm{SWH})^{2}\left(\mathrm{r}^{2}=0.99\right) & (5) \\
\text { EM.B. }(\mathrm{cm})=-.027-2.26 * \lambda_{3}-9.24 * \lambda_{3}{ }^{2} & \left(\mathrm{r}^{2}=0.98\right) & (6) \\
\text { EM.B. }(\mathrm{cm})=-.083-42.5^{\star} \S-2455 .^{\star} \S^{2} & \left(\mathrm{r}^{2}=0.95\right) & (7)
\end{array}
$$

r2 being the square of the correlation coefficient between the regression curve and the measured values. $U$ is in $\mathrm{m} / \mathrm{s}$ and $\mathrm{SWH}$ is in $\mathrm{cm}$.

The variations of the E.M. Bias as a percentage of SWH are shown on figure 4. Ignoring the smallest values which correspond to a very small wind velocity $(\mathrm{U}=1.7 \mathrm{~m} / \mathrm{s})$, the correlations with each of the previous parameters seem more to be linear than quadratic. They yield:

$$
\begin{array}{lll}
\text { EM.B. }(\% S W H)=-4.85 & -.78 * \mathrm{U} & \left(\mathrm{r}^{2}=0.98\right) \\
\text { EM.B.(\%SWH })=-6.38-.96 * \text { SWH } & \left(\mathrm{r}^{2}=0.96\right) \\
\text { EM.B. }(\% S W H)=+.92-30 . * \lambda_{3} & \left(\mathrm{r}^{2}=0.96\right) \\
\text { EM.B. }(\% S W H)=+.45-466 .{ }^{*} \S & \left(\mathrm{r}^{2}=0.97\right)
\end{array}
$$

$\mathrm{U}$ is in $\mathrm{m} / \mathrm{s}$ and SWH is in $\mathrm{cm}$. Note that JACKSON's theoretical law predicts: EM.B.(\%SWH) $=-25 . * \lambda_{3}([6])$ and HUANG's first order theoretical law predicts: EM.B. $(\% S W H)=-100 * \pi * \S([7])$

The variations above will be discussed in detail in [3]. The discussions will take benefit of theoretical or semiempirical relationships established within the field of wind waves development ([8], [9], [10]).

\section{PRELIMINARY DISCUSSIONS}

While the bias from fields observations remains generally smaller than about $5 \%$ of $\mathrm{SWH}$, laboratory measurements yield significantly larger values. In addition, these values evolue rapidly with respect to $\mathrm{U}$, SWH, etc... If we want to predict the E.M. Bias with the algorithm: "EM.B.(\%SWH) $=-\mathrm{a}-\mathrm{b} * \mathrm{U} ", \mathrm{~b}$ should be of order 0.8 in the tank and of order 0.2 in open field [11]. Clearly neither U nor SWH can be taken as a single parameter to account for all observed bias variations. A dimensionless variable characterizing the state of development of the wind wave fields need clearly to be introduced. At least the influence of the fetch have to be considered explicitly or implicitly. The respective bias from laboratory and fields observations would correspond to different ranges of appropriate parameters. This is preliminarly illustrated by figures 5 and 6 which report on our laboratory results together with some values from fields observations ([11], [12], [13]). The parameters are respectively the wave height skewness $\lambda_{3}$ and the adimensionless significant height, $\mathrm{g} * \mathrm{SWH} / \mathrm{U}^{2}$, introduced by Rodriguez [14], related with the dimensionless fetch, $\mathrm{g}^{*} \mathrm{X} / \mathrm{U}^{2}$

Within extended ranges of parameters values, the continuous variations of the bias is quite striking. This would be of crucial interest to determine the bias evolutions with much higher accuracy. Detailed investigation in that matter is under way.

Acknowledgments: the authors are particularly grateful to Dr C. Parsons who generously lent them the dielectric lens. We especially thank B. Zucchini for his diligent laboratory work.

This work was supported by C.N.E.S. (Centre National d'Etudes Spatiales), contract $N^{\circ} 90 / 8002 / 854$, by O.N.R. contract $\mathrm{N}^{\circ} 146 / 70 / 03$, and by N.A.S.A. contract $N^{\circ} 161 / 80 / 23$.

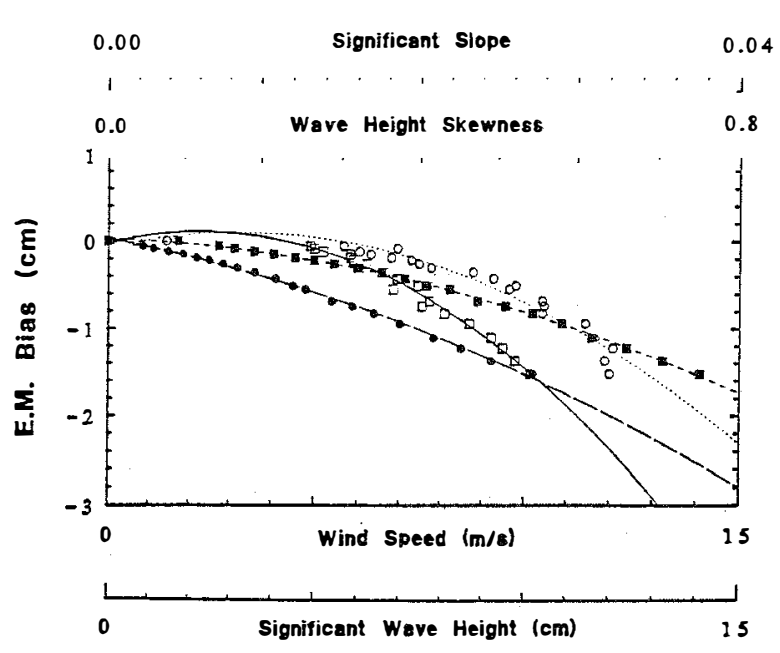

Figure 3: The absolute E.M. Bias (cm) as a function of wind speed ( ), significant wave height ( ), waveheight skewness ( $(\mathrm{)})$ and significant slope (O).

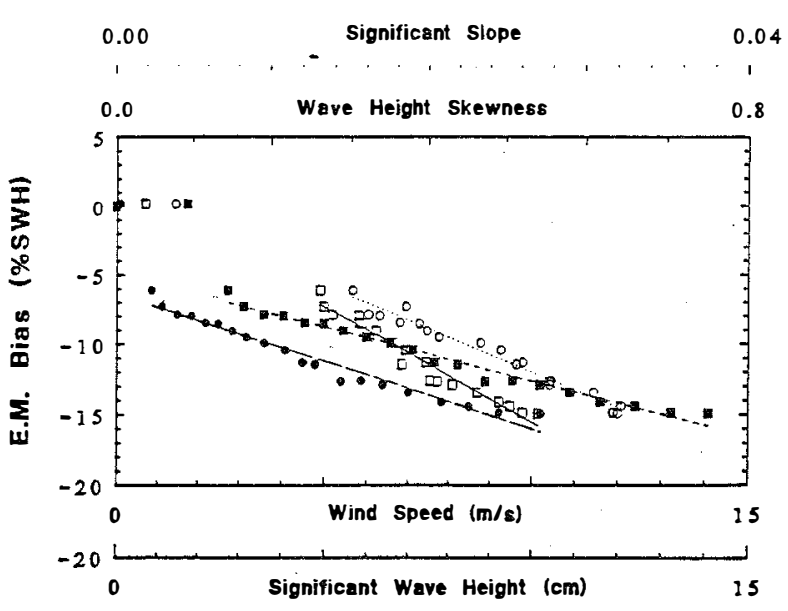

Figure 4: as in figure 3 except E.M. Bias(\%SWH) replaces E.M. Bias $(\mathrm{cm})$.

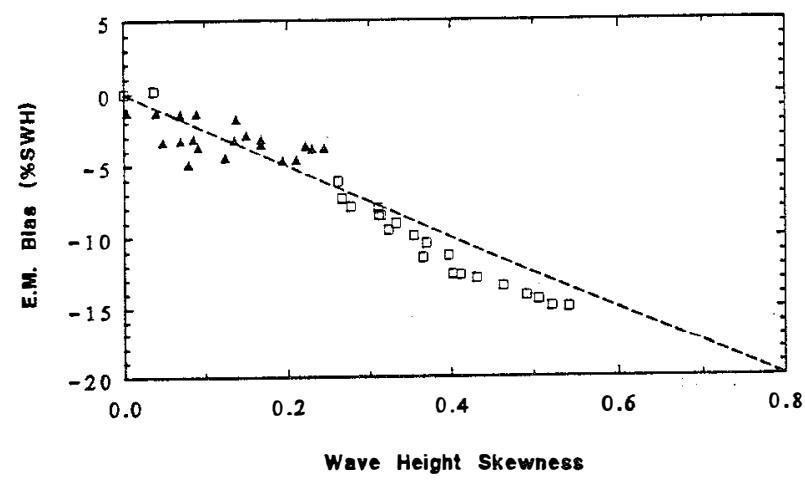

Figure 5: The relative E.M. Bias(\%SWH) as a function of waveheight skewness: $\square$ Laboratory; 1 field (Choy et al [12]);---JACKSON's theoretical law ([6]) 


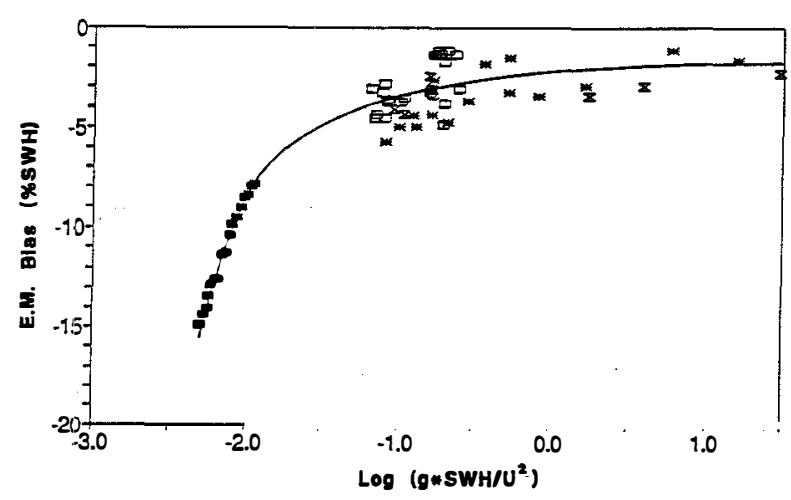

Figure 6: The relative E.M. Bias(\%SWH) as a function of the dimensionless significant waveheight $\mathrm{g} * \mathrm{SWH} / \mathrm{U}^{2}$ : Laboratory; * Melville et al [11]; $\mathbf{z}$ Melville et al [13]; DChoy et al [12]; - average curve estimated from these data
[12] L.W. Choy, D.L. Hammond and E.A. Uliana, "E.M. Bias of $10 \mathrm{GHz}$ radar altimeter measurements of M.S.L.", Mar. Geod., Vol 8, pp 297-312, 1984.

[13] W.K. Melville, D.V. Arnold, R.H. Stewart, W.C Keller, J.A. Kong, A.J. Jessup, M.R. Loewen and E. Delamarre, "Measurements of E.M. Bias at $\mathrm{Ku}$ and $\mathrm{C}$ bands", (in preparation), 1991.

[14] E. Rodriguez and B. Chapman, "Ocean Skewness and the Skewness Bias in Altimetry: a Geosat study", Int. J.Rem. Sens. (to appear), 1991.

\section{REFERENCES}

[1] C.L. Parsons and L.S. Miller, "A laboratory study of the E.M. Bias of Rough Surface Scattering by water waves", IEEE Tr. on Geoscience and Rem. Sens., vol 28, No 6, pp 1001-1011, Nov 1990.

[2] L.F. Bliven, J.P. Giovanangeli and G. Norcross, "A study of rain effect on radar scattering from water waves", 7th conf. on Ocean-Atmos. Interaction, Atm. Met. Soc., ANAKEIN, Californnia, 1-5 Fev 1988.

[3] H. Branger, A. Ramamonjiarisoa, and L. Bliven, "An investigation on electromagnetic bias in radar altimetry", (in preparation), 1991.

[4] A. Lifermann, Doctoral dissertation, University Paul Sabatier, Toulouse, 1987.

[5] P. Bonmarin, "Geometric properties of deep-water breaking waves, J. Fluid. Mech., 209, pp 405-433, 1989.

[6] F.C. Jackson, "The reflexion of impulses from a non linear random sea", J. Geoph. Res., Vol 84, C8, pp 4939-4943, Aug 1979.

[7] N.E. Huang, S.R. Long and C.C. Tung, "The non Gaussian joint probability density function of slope and elevation for a non linear gravity wave field", $J$. Geoph. Res., Vol 89, C2, pp 1961-1972, March 1984.

[8] H.U. Sverdrup and W.H. Munk, "Wind, Sea and Swell", US Hydrogr. Off. Wash. Pub. N\%01, 1947

[9] J.W. Deardorff, "Aerodynamic theory of wave growth with constant wave steepness", J. of Oceano. Soc. of Japan, 23, $N^{\circ}$ 6, pp.278-297, 1967.

[10] K. Hasselmann and XV al., "Measurements of wind wave growth and swell decay during JONSWAP", Herausgegeben vom Deutch Hydrograph. Institut., Reihe A, N¹2, pp.95, 197.3.

[11] W.K. Melville, R.H. Stewart, W.C. Keller, J.A. Kong, D.V. Arnold, A.J. Jessup, M.R. Loewen and A.M. Slinn, "Measurements of E.M. Bias in Radar Altimetry", J. Geoph. Res., in press, 1991 